\title{
Plasmid-based controls to detect rpoB mutations in Mycobacterium tuberculosis by quantitative polymerase chain reaction-high-resolution melting
}

\author{
Joas Lucas da Silva ${ }^{1}{ }^{+}$, Gabriela Guimaraes Sousa Leite', Gisele Medeiros Bastos ${ }^{1}$, \\ Beatriz Cacciacarro Lucas ${ }^{1}$, Daniel Keniti Shinohara ${ }^{1}$, Joice Sayuri Takinami ${ }^{1}$, Marcelo Miyata ${ }^{1}$, \\ Cristina Moreno Fajardo', André Ducati Luchessi', Clarice Queico Fujimura Leite ${ }^{2}$, \\ Rosilene Fressatti Cardoso ${ }^{3}$, Rosario Dominguez Crespo Hirata', Mario Hiroyuki Hirata ${ }^{1}$
}

'Faculdade de Ciências Farmacêuticas, Universidade de São Paulo, São Paulo, SP, Brasil ²Faculdade de Ciências Farmacêuticas, Universidade

Estadual Paulista, Araraquara, SP, Brasil 'Departamento de Análises Clínicas, Universidade Estadual de Maringá, Maringá, PR, Brasil

Quantitative polymerase chain reaction-high-resolution melting (qPCR-HRM) analysis was used to screen for mutations related to drug resistance in Mycobacterium tuberculosis. We detected the C526T and C531T mutations in the rifampicin resistance-determining region (RRDR) of the rpoB gene with qPCR-HRM using plasmid-based controls. A segment of the RRDR region from M. tuberculosis H37Rv and from strains carrying C531T or C526T mutations in the $\mathrm{rpoB}$ were cloned into $p G E M-T$ vector and these vectors were used as controls in the qPCR-HRM analysis of $54 \mathrm{M}$. tuberculosis strains. The results were confirmed by DNA sequencing and showed that recombinant plasmids can replace genomic DNA as controls in the qPCR-HRM assay. Plasmids can be handled outside of biosafety level 3 facilities, reducing the risk of contamination and the cost of the assay. Plasmids have a high stability, are normally maintained in Escherichia coli and can be extracted in large amounts.

Key words: drug resistance - rifampicin - Mycobacterium tuberculosis

The development of rapid and affordable assays for diagnosing multidrug-resistant tuberculosis (TB) is necessary to control the spread of the disease (Bwanga et al. 2009). The rapid detection of Mycobacterium tuberculosis reduces treatment failure, the rate of transmission and the period of infectiousness (Martin et al. 2008, Koh et al. 2012).

High-resolution melting (HRM) analysis can be used to distinguish DNA sequences with slight differences in the melting curve profile. This technique measures the fluorescence of a DNA dye released from doublestranded DNA with high accuracy (Ghorashi et al. 2010). HRM analysis has been used in screens for gene mutations prior to DNA sequencing, in methylation studies and for genotyping, with high throughput, reliability, rapidity, simplicity and cost efficiency (Ereqat et al. 2010, Kagkli et al. 2012).

A number of DNA deletions, insertions and singlenucleotide polymorphisms in the $M$. tuberculosis genome are well established as causing resistance to antiTB drugs (Nimri et al. 2011, Malik et al. 2012). HRM analysis of these mutations are useful for the rapid pre-

\footnotetext{
Financial support: FAPESP, CNPq

JLS and MM are recipients of fellowships from FAPESP. MHH, RDCH, $\mathrm{BCL}, \mathrm{DKS}$ and $\mathrm{ADL}$ are recipients of fellowships from CNPq.

+ Corresponding author: joaslucas@usp.br

Received 5 April 2012

Accepted 8 August 2012
}

diction of the drug sensitivity profile and, consequently, allow for the adjustment of treatment regimens (Ramirez et al. 2010, Lee et al. 2012, Yadav et al. 2012).

Rifampicin is considered a good marker for multidrug resistance. This drug binds to the $\beta$-subunit of RNA polymerase encoded by $r p o B$ and inhibits DNA-directed RNA synthesis. Mutations in the $r p o B$ gene are associated with rifampicin resistance and are usually located within an $81 \mathrm{bp}$ hypervariable region of the $\operatorname{rpoB}$ gene known as the rifampicin resistance-determining region (RRDR) (Khadka et al. 2011, Nimri et al. 2011). Quantitative polymerase chain reaction-HRM (qPCR-HRM) analysis of the RRDR locus can be used to rapidly screen for $r p o B$ mutations (Ong et al. 2010, Yadav et al. 2012).

To improve the specificity of HRM analysis, genomic DNA samples with specific mutations are used as positive or negative controls (Choi et al. 2010, Ong et al. 2010). However, the production of large amounts of genomic DNA carrying resistance-associated mutations must be performed in a biosafety level 3 laboratory. Cloning strategies that allow for the large-scale production of recombinant DNA in Escherichia coli or other less pathogenic bacteria may provide a useful method to obtain M. tuberculosis mutant sequences that will improve the performance of HRM analysis.

In this study, plasmids carrying the C526T or C531T mutation or no mutations in the RRDR region of $r p o B$ were cloned into the pGEM-T easy vector and used as positive and negative controls, respectively, in the HRM assays.

A total of 54 M. tuberculosis isolates were obtained from our $M$. tuberculosis collection. Rifampicin susceptibility was determined by the resazurin microtitre 
assay (REMA) plate method according to Palomino et al. (2002). The rifampicin susceptibility profile was also obtained by the nonradiometric BACTEC MGIT 960 method (BD, USA) (Miyata et al. 2011).

Mycobacterial DNA was extracted using a QIAamp DNA mini kit (Qiagen, USA) according to the manufacturer's instructions. The primers RpFw 5'-GTCGGCGAGCTGATCCAAAAC-3' and RpRv 5'-GGTACGGCGTTTCGATGAACC-3' (IDT, USA) were designed using Primer Premier software 5.0 (Biosoft, USA) to amplify a 409-bp segment of $r p o B$ containing the RRDR region. PCR assays were performed with a PTC 200 thermocycler (MJ Research, USA) under the following cycling conditions: (i) an initial step at $95^{\circ} \mathrm{C}$ for $10 \mathrm{~min}$, (ii) 30 cycles at $95^{\circ} \mathrm{C}$ for $45 \mathrm{~s}, 58^{\circ} \mathrm{C}$ for $30 \mathrm{~s}$ and $72^{\circ} \mathrm{C}$ for $1 \mathrm{~min}$ and (iii) a 10 -min step at $72^{\circ} \mathrm{C}$.

The PCR products were purified with a QIAquick PCR purification kit (Qiagen, USA) and sequenced with an ABI 3730 DNA Analyser using the BigDye Terminator v3.1 Cycle Sequencing Kit (Applied Biosystems, USA) and the previously described set of primers. The sequence was analysed with BioEdit software v7.1.3 (Ibis Biosciences, USA). The 409-bp segment was cloned into the pGEM-T Easy Vector (Promega, USA) and plasmid DNA was extracted with the Plasmid Midi kit (Qiagen, USA) according to the manufacturer's protocol.

To perform qPCR-HRM, the primers HRM-Fw 5'TCGCCGCGATCAAGGAGTT-3' and HRM-Rv 5'-GTGCACGTCGCGGACCTC-3' (IDT, USA) were designed to amplify a $158 \mathrm{bp}$ segment of $r p o B$ spanning the RRDR region. qPCR-HRM was performed in duplicate on a Rotor-gene 6000 platform (Qiagen, USA) in a reaction mixture containing $10 \mu \mathrm{L}$ of $2 \mathrm{X}$ Amplitaq Gold PCR Master Mix (Applied Biosystems, USA), $1 \mu \mathrm{L}$ of DNA, $200 \mathrm{nM}$ each primer, $0.6 \mu \mathrm{M}$ Syto9 (Invitrogen, USA) and PCRgrade water to a reaction volume of $20 \mu \mathrm{L}$.

Recombinant plasmids and $M$. tuberculosis DNA were diluted to obtain qPCR threshold cycle $(\mathrm{Ct})$ values between 19-29 (Ramirez et al. 2010). The cycling parameters were as follows: one step of $10 \mathrm{~min}$ at $95^{\circ} \mathrm{C}$ and 40 cycles of $20 \mathrm{~s}$ at $95^{\circ} \mathrm{C}$ and $1 \mathrm{~min}$ at $62^{\circ} \mathrm{C}$. HRM was performed with an initial step at $60^{\circ} \mathrm{C}$ for $1 \mathrm{~min}$ followed by temperature increases over the range of $65-95^{\circ} \mathrm{C}$ at a rate of $0.1^{\circ} \mathrm{C} / \mathrm{s}$ with constant fluorescence acquisition.

The PCR and HRM results were analysed using Rotor-gene 6000 software v. 2.0.2 (Qiagen, USA). The melting curves were analysed using Rotor-gene ScreenClust HRM software (Qiagen, USA). This software was used to optimise the assay and group the samples. The DNA sequencing of the recombinant plasmids pGEM-C526T, pGEM-C531T and pGEM-wild type (WT) containing the rро $B$ coding segment confirmed the expected sequences and no additional mutations that could interfere with the melting curve profiles were found.

The concentrations of plasmid and genomic DNA with Cts between 19-29 provided accurate data for the qPCR-HRM analysis. Similar results were obtained by Ramirez et al. (2010) using genomic DNA. PCR products that were directly amplified from M. tuberculosis H37Rv genomic DNA presented the same melting curve profile as pGEM-WT. Moreover, it was possible to discriminate

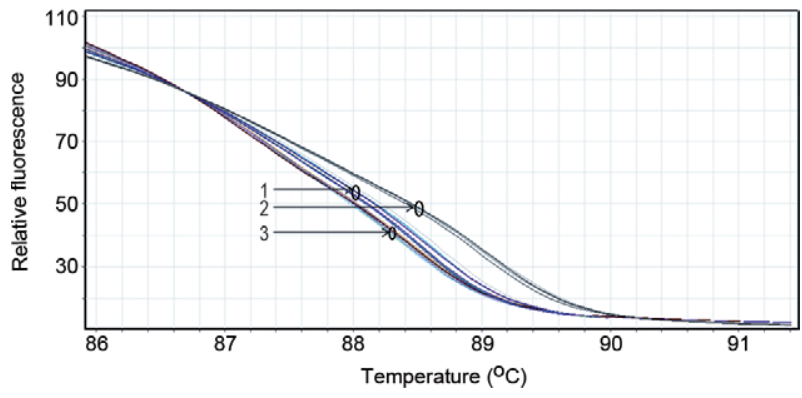

Fig. 1: quantitative polymerase chain reaction-high-resolution melting profiles of recombinant plasmids. Normalized fluorescence vs. temperature of the $158 \mathrm{bp}$ segment from Mycobacterium tuberculosis genomic DNA and recombinant plasmids. 1: pGEM-C526T and genomic DNA of $M$. tuberculosis carrying mutation C526T; 2: pGEMWT and M. tuberculosis $\mathrm{H}_{37} \mathrm{R}_{\mathrm{v}}$ genomic DNA; 3: pGEM-C531T and genomic DNA carrying mutation C531T.

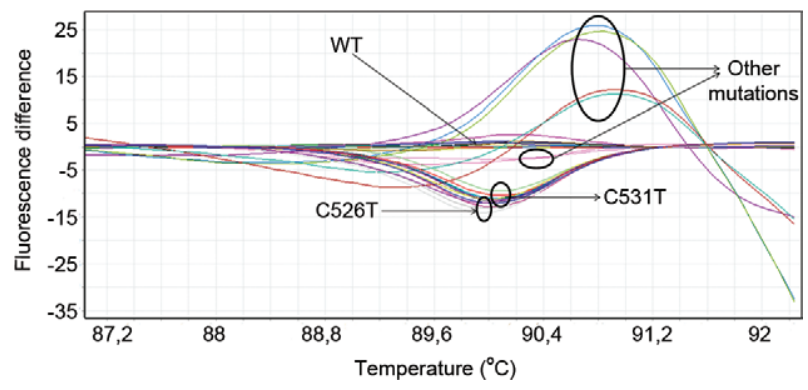

Fig. 2: quantitative polymerase chain reaction-high-resolution melting profiles of DNA samples. Differential plots of the $158 \mathrm{bp}$ segment of rрoB from Mycobacterium tuberculosis genomic DNA and recombinant plasmids. 1: pGEM-wild type and M. tuberculosis $\mathrm{H}_{37} \mathrm{R}$ genomic DNA, C526T; 2: pGEM-C526T and genomic DNA of M. tuberculosis samples carrying mutation C526T, C531T; 3: pGEM-C531T and genomic DNA samples carrying mutation C531T. Variations: samples presenting other mutations.

pGEM-WT from pGEM-C526T, pGEM-C531T and $M$. tuberculosis genomic DNA with other mutations. In addition, the recombinant plasmids pGEM-C526T and pGEM-C531T had the same melting curve profiles as M. tuberculosis genomic DNA carrying the C526T and C531T mutation, respectively (Fig. 1).

Visual discrimination of the melting curve profiles of pGEM-C526T and pGEM-C531T was difficult due to the nucleotide change being the same and the proximity of the mutations in the DNA strand. However, the software used to analyse data was able to accurately distinguish these mutations. The detection of slight differences in the melting curve profile of two different mutations is important to specifically detect only mutations associated with phenotypic drug resistance profiles (Figs 1, 2). These results revealed that recombinant plasmids can replace genomic DNA as positive and negative controls in the detection of the two main mutations in the RRDR region correlated with phenotypic rifampicin resistance without interfering with the data interpretation. 


\section{TABLE}

Rifampicin phenotypic profile of Mycobacterium tuberculosis strains and detection of mutations (C526T and C531T) in the rifampicin resistance-determining region obtained

by quantitative polymerase chain reaction-high-resolution melting (qPCR-HRM) and confirmed by DNA sequencing

\begin{tabular}{lcccc}
\hline & & & \multicolumn{2}{c}{$\begin{array}{c}\text { Rifampicin phenotypic profile } \\
\text { (resazurin microtitre assay) }\end{array}$} \\
Sequence & qPCR-HRM & $\begin{array}{c}\text { DNA } \\
\text { sequencing }\end{array}$ & Susceptible & Resistant \\
\hline Mutation C526T & 3 & 3 & - & 3 \\
Mutation C531T & 15 & 15 & - & 15 \\
Other mutations & 12 & 12 & 18 & 6 \\
No mutation & 24 & 24 & & 54 \\
\hline Total of strains & 54 & 54 & & 6 \\
\hline
\end{tabular}

The plasmid-based controls were used to screen for C526T and C531T mutations in the RRDR region of 54 M. tuberculosis strains. The qPCR-HRM results gave four curve profiles that allowed for the mycobacterial strains to be divided into four groups: (i) WT, (ii) C531T mutation, (iii) C526T mutation and (iv) other mutations. This fourth group contained all of the samples with mutations other than C526T and C531T (Table).

The RRDR regions of all strains were sequenced. The results confirmed that $100 \%$ of the strains with mutations were correctly typed as carrying the C526T or C531T mutation or other mutations (Table). The plasmidbased controls had high specificities; pGEMT-WT was able to differentiate all WT strains from strains with nucleotide changes. Strains presenting the C526T or C531T mutation were easily identified using their respective plasmids and no strains with other mutations were included in groups 1,2 or 3.

Mutations in the RRDR region are usually found in clinical isolates resistant to rifampicin and most of these mutations occur in codons 516, 526 and 531 (Lingala et al. 2010, Khadka et al. 2011, Yadav et al. 2012). In this study, six strains with no mutations in the RRDR region of $r p o B$, but that were rifampicin resistant according to the REMA, were identified as WT by the HRM analysis and DNA sequencing. This resistance could be due to mutations in other regions of the M. tuberculosis genome that were not evaluated in this study (Siu et al. 2011). In addition, two strains presenting mutations in the RRDR and included in group 4 were susceptible to rifampicin according to the REMA, but resistant to rifampicin according to the nonradiometric BACTEC MGIT 960 gold standard method (Miyata et al. 2011). DNA sequencing showed a single mutation (C531G) in the RRDR of one strain, whereas two mutations (C505T and C526T) were found in the second strain. These findings confirm the BACTEC MGIT susceptibility results and show that the $\mathrm{C} 531 \mathrm{G}$ and $\mathrm{C} 526 \mathrm{~T}$ mutations are related to rifampicin resistance (Mark et al. 2005). Additionally, the presence of the C531G or C505T mutation in the $158 \mathrm{bp}$ segment generated a specific melting curve profile for each strain and, therefore, these strains were correctly classified into group 4 by the qPCR-HRM analysis. The inclusion of new plasmid controls for other nucleotide changes that cause rifampicin resistance will certainly reduce the number of samples placed in group 4.

In contrast to some molecular methods, HRM analysis can be easily adapted to accurately detect mutations according to the necessities of each region or country. Plasmid libraries can be developed with gene mutations that are frequently related to drug resistance and stored for a long time in large quantities. These libraries can be easily maintained in $E$. coli, which can be grown in inexpensive media. There is no need to frequently grow drug-resistant $M$. tuberculosis strains exclusively for extracting DNA samples for use as reference sequences.

The detection of drug resistance with qPCR-HRM using plasmid controls requires less than $3 \mathrm{~h}$ for completion, whereas phenotypic assays usually take more than a week. A rapid test to detect drug resistance has the potential to greatly improve the quality of TB treatment because the patient will receive the correct drug, the treatment cost will be lower and the probability of spreading multidrug-resistant TB will be reduced.

In conclusion, plasmid-based controls are a good alternative for the routine detection of known mutations associated with drug resistance using qPCR-HRM.

\section{REFERENCES}

Bwanga F, Hoffner S, Haile M, Joloba ML 2009. Direct susceptibility testing for multidrug resistant tuberculosis: a meta-analysis. BMC Infect Dis 9: 67.

Choi GE, Lee SM, Yi J, Hwang SH, Kim HH, Lee EY, Cho EH, Kim JH, Kim H, Chang CL 2010. High-resolution melting curve analysis for rapid detection of rifampicin and isoniazid resistance in Mycobacterium tuberculosis clinical isolates. J Clin Microbiol 48: 3893-3898.

Ereqat S, Bar-Gal GK, Nasereddin A, Azmi K, Qaddomi SE, Greenblatt CL, Spigelman M, Abdeen Z 2010. Rapid differentiation of Mycobacterium tuberculosis and $M$. bovis by high-resolution melt curve analysis. J Clin Microbiol 48: 4269-4272.

Ghorashi SA, Noormohammadi AH, Markham PF 2010. Differentiation of Mycoplasma gallisepticum strains using PCR and highresolution melting curve Analysis. Microbiology 156: 1019-1029. 
Kagkli DM, Folloni S, Barbau-Piednoir E, Van den Eede G, Van den Bulcke M 2012. Towards a pathogenic Escherichia coli detection platform using multiplex Sybr green real-time PCR methods and high resolution melting analysis. PLOS ONE 7: e39287.

Khadka JB, Rai SK, Shrestha S, Maharjan B, Bhatta DR, Ghimire P 2011. Study of rifampicin and isoniazid resistance mutation genes of M. tuberculosis isolates in Nepal Nepal Med Coll J 13: 147-151.

Koh WJ, Ko Y, Kim CJ, Park KS, Lee NY 2012. Rapid diagnosis of tuberculosis and multidrug resistance using a MGIT 960 system. Ann Lab Med 32: 264-269.

Lee AS, Ong DC, Wong JC, Siu GK, Yam WC 2012. High-resolution melting analysis for the rapid detection of fluoroquinolone and streptomycin resistance in Mycobacterium tuberculosis. PLoS ONE 7: e31934.

Lingala MAL, Srikantam A, Jain S, Rao KVSM, Rao PVR 2010. Clinical and geographical profiles of rpoB gene mutations in $M y$ cobacterium tuberculosis isolates from Hyderabad and Koraput in India. J Microbiol Antimicrob 2: 13-18.

Malik S, Willby M, Sikes D, Tsodikov OV, Posey JE 2012. New insights into fluoquinolone resistance in Mycobacterium tuberculosis: functional genetic analysis of gyrA and gyr B mutations. PLoS ONE 7: e39754.

Mark TM, Gillette JS, Thomas DP, Ramaswamy SV, Graviss EA, Kreiswirth BN, Vijg, J, Quitugua TN 2005. Detection of $\operatorname{rpo} B$ mutations associated with rifampin resistance in Mycobacterium tuberculosis using denaturing gradient gel electrophoresis. Antimicrob Agents Chemother 49: 2200-2209.

Martin A, Panaiotov S, Portaels F, Hoffner S, Palomino JC, Angeby $\mathrm{K} 2008$. The nitrate reductase assay for the rapid detection of iso- niazid and rifampicin resistance in Mycobacterium tuberculosis: a systematic review and meta-analysis. $J$ Antimicrob Chemother 48: $1047-1052$.

Miyata M, Pavan FR, Sato DN, Marino LB, Hirata MH, Cardoso RFM, Fiúza FA, Zanelli CF, Leite CQF, Miyata M 2011. Drug resistance in Mycobacterium tuberculosis clinical isolates from Brazil: phenotypic and genotypic methods. Biomed Pharmacother 65: 456-459.

Nimri L, Batchoun S, Batchoun R 2011. Detection of mutations associated with multidrug-resistant Mycobacterium tuberculosis clinical isolates. FEMS Immunol Med Microbiol 62: 321-332.

Ong DCT, Yam W, Siu GKH, Lee ASG 2010. Rapid detection of rifampicin and isoniazid-resistant Mycobacterium tuberculosis by high-resolution melting analysis. J Clin Microbiol 48: 1047-1052.

Palomino JC, Martin A, Camacho M, Guerra H, Swings J, Portaels F 2002. Resazurin microtiter assay plate: simple and inexpensive method for detection of drug resistance in Mycobacterium tuberculosis. Antimicrob Agents Chemother 46: 2720-2722.

Ramirez MV, Cowart KC, Campbell PJ, Morlock GP, Sikes D, Winchell JM, Posey JE 2010. Rapid detection of multidrug-resistant Mycobacterium tuberculosis by real-time and high-resolution melt analysis. J Clin Microbiol 48: 4003-4009.

Siu GK, Zhang Y, Lau TC, Lau RW, Ho PL, Yew WW, Tsui SK, Cheng VC, Yuen KY, Yam WC 2011. Mutations outside the rifampicin resistance-determining region associated with rifampicin resistance in Mycobacterium tuberculosis. J Antimicrob Chemother 66: $730-733$.

Yadav R, Sethi S, Mewara A, Dhatwalia SK, Gupta D, Sharma M 2012. Rapid detection of rifampicin, isoniazid and streptomycin resistance in Mycobacterium tuberculosis clinical isolates by high resolution melting curve analysis. J Appl Microbiol 113: 856-862. 